\title{
SOCIODEMOGRAPHIC AND LIFESTYLE ASPECTS VERSUS ACCESS TO TREATMENT FOR PATIENTS WITH BREAST CANCER AT A CANCER CENTER IN SÃO PAULO
}

José Euderaldo Costa Gomes Filho1, Ariane Silva da Rocha1, Gisele Aparecida Fernandes¹, Rossana Verónica Mendoza López¹, Maria Paula Curado ${ }^{1}$

${ }^{1}$ AC Camargo Cancer Center - São Paulo (SP), Brazil.

Sociodemographic and lifestyle aspects versus access to breast cancer treatment - Single Health System (SHS) and Supplementary Health - were evaluated in a prospective cohort of patients with breast cancer. This is a cross-sectional study with 705 patients. As compared with sociodemographic characteristics, $56.5 \%$ ( $\mathrm{n}=398)$ of the patients were seen through Supplementary Health, and for both SHS and Supplementary Health patients, there is a higher frequency of women aged above 50 years, with 62.2\% $(n=191)$ and $51 \%(n=203)(p=0.002)$; married, $48.2 \%(n=148)$ and 66.6\% $(n=265)(p<0.001)$; white, 69.4\% ( $\mathrm{n}=213)$ and $82.1 \%(\mathrm{n}=325)(\mathrm{p}<0.001)$; and for the level of education, 37.1\% ( $\mathrm{n}=114)$ of those with SHS had completed high school and $55.7 \%$ ( $\mathrm{n}=221)(\mathrm{p}<0.001)$ of those with Supplementary Health had completed college. The first mammogram occurred between the ages of 18 and 40 years, 72.5\% $(\mathrm{n}=206)$ of the SHS participants and 88.6\% $(\mathrm{n}=342)(\mathrm{p}<0.001)$ for Supplementary Health; own housing for 90.6\% ( $\mathrm{n}=278)$ and $89.4 \%(\mathrm{n}=354)(\mathrm{p}<0.001)$; denied tobacco use, $65.5 \%(\mathrm{n}=201)$ and 74.7\% ( $\mathrm{n}=296)(\mathrm{p}=0.005)$; and alcohol consumption, 87.6\% $(\mathrm{n}=269)$ and $77.2 \%(\mathrm{n}=305)(\mathrm{p}<0.001)$. However, there was no difference regarding previous diagnosis of breast cancer in $55.3 \%(n=114)$ and $64 \%(n=178)(p<0.001)$ and the type of care; eutrophic body mass index was $38.4 \%(n=118)$ and $42.1 \%(n=167)(p=0.079)$, respectively. Access to SHS and supplementary health care, age above 50 years, married, white, level of education, age at first mammogram, home ownership, smoking habits, and consumption of alcoholic beverages were significantly different; BMI was not different in the two groups. Therefore, the lifestyle of SHS and Supplementary Health patients was statistically different in this cohort of patients.

Keywords: Breast Cancer; Lifestyle; Public Health. 